\title{
Chiral oxazolidine complexes derived from phenolic
}

\section{Schiff bases.}

Júlia Mayans, ${ }^{\ddagger, \#}$ Daniel Gómez, ${ }^{\ddagger}$ Mercè Font-Bardia, ${ }^{\#}$ Albert Escuer, ${ }^{*, \neq}$

* Departament de Química Inorgànica i Orgànica, Secció Inorgànica and Institut de Nanociència i Nanotecnologia (IN²UB), Universitat de Barcelona, Martí i Franqués 1-11, Barcelona-08028, Spain.

¥ Instituto de Ciencia Molecular (ICMol), Universitat de València, c/ Catedrático José Beltrán 2, 46980 Paterna (València), Spain.

\# Departament de Mineralogia, Cristal·lografia i Dipòsits Minerals, Universitat de Barcelona, Martí Franqués s/n, 08028 Barcelona (Spain) and Unitat de Difracció de R-X. Centre Científic i Tecnològic de la Universitat de Barcelona (CCiTUB), Solé i Sabarís 1-3. 08028 Barcelona. 


\begin{abstract}
Schiff bases derived from pyridyl- or salicyl- aldehydes and aminoalcohols can evolve to heterocyclic oxazolidines which, in the presence of cations allow the formation of uncommon coordination compounds. In this work, we report new $\mathrm{Ni}^{\mathrm{II}}$ and mixed valence $\mathrm{Mn}^{\mathrm{II}} / \mathrm{Mn}^{\mathrm{IV}}$ complexes derived from pyridyl oxazolidines and the unprecedented characterization of enantiomerically pure oxazolidines derived from the condensation of $O$-vanillin with phenylglycinol in the presence of $\mathrm{Ni}^{\mathrm{II}}$ cations. The different reactivity of the pyridinic or phenolic Schiff bases has been compared and the new systems have been structural, optical and magnetically characterized.
\end{abstract}

\title{
INTRODUCTION
}

Schiff bases are versatile ligands that, depending on the starting carbonyl and amino fragments used for the condensation, can exhibit an enormous variety of properties such as different kind and number of $\mathrm{N}, \mathrm{O}$-donors, different charge or different predefined shapes (linear, cyclic, compartmental, etc.). This versatility can be very useful in the definition of the topology and properties of the derived coordination complexes. ${ }^{1,2}$ More concretely, the reaction of ketones or aldehydes with 1,2-aminoalcohols is a simple method to prepare a large variety of Schiff bases ${ }^{3}$ but in some cases, a further nucleophilic attack of the alkoxo group on the iminic $\mathrm{C}$-atom takes place. Thus, instead of the usual condensation it allows the formation of oxazolidines, which consist in one saturated heterocyclic five-membered NCOCC ring. Oxazolidines are less studied than the related unsaturated oxazoles or oxazolines despite that the organic molecules or their 
coordination compounds offer promising possibilities in different applied fields like medicinal chemistry $^{4,5}$ or catalysis. ${ }^{6-10}$

Reaction of pyridine- or quinolinealdehyde with tris(hydroxymethyl)aminomethane (TRIS) is one of the reactions that, usually in the presence of metallic cations, tends to produce oxazolidines instead of the corresponding Schiff bases. The number of coordination complexes derived from 2-pyridinecarboxaldehyde ${ }^{11-13}$ or quinolinealdehydes, ${ }^{14-16}$ often mononuclear systems, is limited but has been characterized for several $3 d$ cations along the last years. However, this catalysed formation of the oxazolidine has not been reported yet when using salicylaldehyde or the related $o$-vanillin as starting carbonyl source.

Recently, our group has developed a research line on coordination compounds derived from Schiff bases, mainly focused on chiral systems starting from enantiopure reactants. ${ }^{17-20}$ During this period, the reactions of 2-pyridinecarboxaldehyde with TRIS or $O$-vanillin with enantiomerically pure $(R)$ or $(S)$-phenylglycinol, designed for the synthesis of Schiff base/azide clusters, allowed us to the characterization in good yield of the derived oxazolidine complexes containing the ligands $\mathrm{H}_{3} \mathrm{~L} 3$ and $\mathrm{H}_{2} \mathrm{~L} 4$, instead of the expected $\mathrm{H}_{3} \mathrm{~L} 1$ and $\mathrm{H}_{2} \mathrm{~L} 2$ bases depicted in Chart 1. The later ligand, $\mathrm{H}_{2} \mathrm{~L} 4$, becomes particularly interesting because, on one hand, the example presented here is the first case in which one oxazolidine has been obtained from this kind of Schiff bases and, on the other hand, its chiral character leads to selective characterization of two enantiomeric oxazolidines. 
Chart 1. Precursor Schiff bases and the derived oxazolidines employed in this work. Asterisk denotes the chiral C-atom of the $\mathrm{H}_{2} \mathrm{~L} 2$ base.
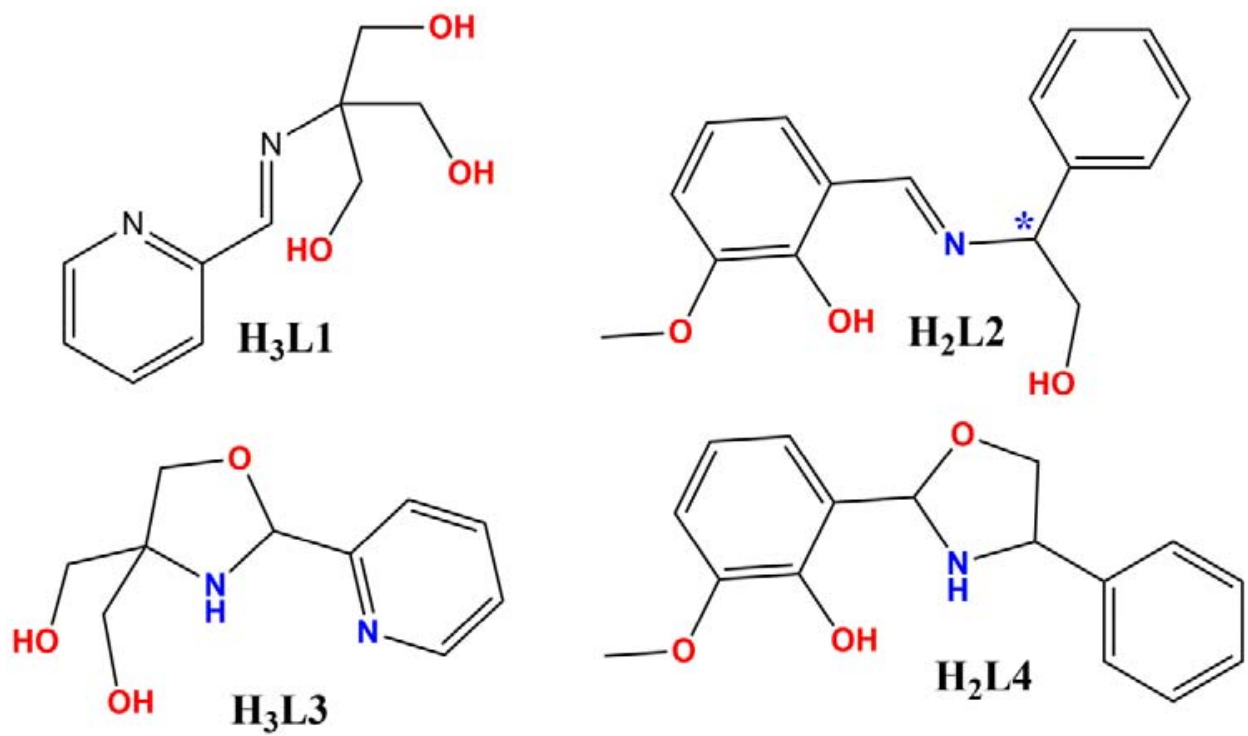

Following with our previous research in this field, we report here the structural characterization of one $\mathrm{Ni}^{\mathrm{II}}$ pyridyl-oxazolidine complex with formula $\left[\mathrm{Ni}_{2}\left(\mathrm{H}_{3} \mathrm{~L} 3\right)_{2}\left(\mu_{11}-\right.\right.$ $\left.\left.\mathrm{N}_{3}\right)_{2} \mathrm{Cl}_{2}\right] \cdot 2 \mathrm{MeOH}$ (1), one 1D mixed valence manganese system with formula $\left[\mathrm{Mn}_{6}{ }_{6} \mathrm{Mn}{ }^{\mathrm{IV}}{ }_{2}(\mathrm{HL} 3)_{6}(\mathrm{HCOO})_{2}\left(\mathrm{~N}_{3}\right)_{4}\left(\mu_{11}-\mathrm{N}_{3}\right)\left(\mu_{13}-\mathrm{N}_{3}\right)\right] \cdot 3 \mathrm{MeOH} \cdot \mathrm{H}_{2} \mathrm{O}$ (2), one $\mathrm{Ni}^{\mathrm{II}}$ complex with formula $\left[\mathrm{Ni}_{4}(\mathrm{~L} 2)_{4}(\mathrm{MeOH})_{4}\right] \cdot 2 \mathrm{MeOH}$ (3) and the enantiomeric pair of phenolic-oxazolidine complexes $\left[\mathrm{Ni}_{2}(\mathrm{HL} 2)_{2}(\mathrm{HL} 4)\left(\mu_{11}-\mathrm{N}_{3}\right)\right] \cdot 2 \mathrm{MeOH} \quad(R)-\mathrm{HL} 4, \quad(\mathbf{4 R}),(S)-\mathrm{HL} 4, \quad(4 \boldsymbol{S})$. Complex 3 contains the Schiff base $\mathrm{L}^{2-}$ and it is included for comparative purposes with the derived oxazolidine systems $\mathbf{4 R}$ and $\mathbf{4 S}$. The reactivity of the Schiff bases towards its respective oxazolidine has been studied and all the systems have been magnetically characterized.

The reported systems exhibit some remarkable features such the different reactivity of the expected Schiff bases in some specific conditions, the larger manganese-oxazolidine complex reported until today, the unusual $\mathrm{Mn}^{\mathrm{II}} / \mathrm{Mn}^{\mathrm{IV}}$ coexistence of manganese cations in oxidation state 
differing by two units and the unprecedented chiral oxazolidine derived from $\mathrm{H}_{2} \mathrm{~L} 2$ family of ligands. These different products with different metals obtained in similar reaction conditions can be, in a near future, a new usual way to prepare oxazolidine-derived complexes and one more step in the study of the occurrence of this synthetic path in the catalytic presence of some transition metals.

\section{EXPERIMENTAL SECTION}

\section{Materials and Physical Measurements.}

2-pyridinecarboxaldehyde, $o$-vanillin and the chiral $(R)$ and $(S)$-phenylglycinol chemicals were purchased to TCI Chemicals and used as received. The syntheses were performed at open air in reagent grade solvents. IR spectra $\left(4000-400 \mathrm{~cm}^{-1}\right)$ were recorded on a Bruker IFS-125 FT-IR spectrometer with samples prepared as $\mathrm{KBr}$ pellets. Variable-temperature magnetic studies were performed using a MPMS5 Quantum Design magnetometer operating at $0.03 \mathrm{~T}$ in the $300-2.0 \mathrm{~K}$ range. Diamagnetic corrections were applied to the observed paramagnetic susceptibility using Pascal constants. Fits of the experimental magnetic measurements were performed with PHI program. ${ }^{21}$ ECD spectra in methanolic solution were recorded on a Jasco- 815 spectropolarimeter.

X-ray crystallography. Details of crystal data, data collection and refinement for complexes $1,2,3 S, 4 R$ and $4 S$ are summarized in ESI Tables S1 and S2. Collection data were made on a Bruker D8 Venture system equipped with a multi-layer monochromator and a Mo microfocus $(\lambda=0.71073 \AA)$. All structures were solved using the Brucker SHELXTL software package and refined with SHELXL computer program. ${ }^{22}$ Data were corrected for absorption effects using the multi-scan method (SADABS). Plots for publication were generated with ORTEP3 for Windows ${ }^{23}$ and plotted with Pov-Ray programs. 
All data can be found in the supplementary crystallographic data for this paper in cif format with CCDC numbers 1993842 - 1993846. These data can be obtained free of charge from The Cambridge Crystallographic Data Centre via www.ccdc.cam.ac.uk/data_request/cif.

Synthesis of the ligands. $\mathbf{H}_{3} \mathbf{L} 1: 10 \mathrm{mmol}(1.07 \mathrm{~g})$ of 2-pyridinecarboxaldehyde and $10 \mathrm{mmol}$ $(1.21 \mathrm{~g})$ of tris(hydroxymethyl)aminomethane (TRIS) were dissolved in $15 \mathrm{~mL}$ of methanol and the mixture was maintained under stirring during one hour at $45^{\circ} \mathrm{C}$. The resulting solution of $\mathrm{H}_{3} \mathrm{~L} 1$ was diluted in $100 \mathrm{~mL}$ of methanol and employed directly in the subsequent reactions without isolation of the ligands. $\mathbf{H}_{\mathbf{2}} \mathbf{L} \mathbf{2}$ was synthesized as previously reported. ${ }^{17-20}$

$\left[\mathbf{N i}_{2}\left(\mathbf{H}_{3} \mathbf{L} 3\right)_{2}\left(\mu_{11}-\mathbf{N}_{3}\right)_{2} \mathbf{C l}_{2}\right] \cdot \mathbf{2} \mathbf{M e O H}(\mathbf{1}) . \mathrm{NiCl}_{2} \cdot 6 \mathrm{H}_{2} \mathrm{O}(0.239 \mathrm{~g}, 1 \mathrm{mmol})$ dissolved in $5 \mathrm{~mL}$ of methanol and sodium azide $(0.064 \mathrm{~g}, 1 \mathrm{mmol})$ were added to $10 \mathrm{~mL}$ of the previously prepared solution of $\mathrm{H}_{3} \mathrm{~L} 1$. The resulting green solution was filtered and layered with diethylether. Wellformed green crystals were collected after 4 days. Yield 60\%. Anal. calculated/found (\%) for complex 1, C, 35.0/34.7; $\mathrm{H} \mathrm{4.5/4.7;} \mathrm{N} 18.6 / 18.3$. IR spectra for all the complexes are reported in Figure S1.

$\left[\mathrm{Mn}_{6}{ }_{6} \mathrm{M}_{n}{ }^{\mathrm{IV}}{ }_{2}(\mathrm{HL3})_{6}(\mathrm{HCOO})_{2}\left(\mathbf{N}_{3}\right)_{4}\left(\mu_{11}-\mathrm{N}_{3}\right)\left(\mu_{13}-\mathrm{N}_{3}\right)\right] \cdot \mathbf{3 M e O H} \cdot \mathbf{H}_{2} \mathrm{O}(2)$. To $10 \mathrm{~mL}(1 \mathrm{mmol})$ of the previously prepared solution of $\mathrm{H}_{3} \mathrm{~L} 1$ were added sodium methoxide dissolved in $5 \mathrm{~mL}$ of methanol $(0.108 \mathrm{~g}, 2 \mathrm{mmol})$, manganese formate $(0.145 \mathrm{~g}, 1 \mathrm{mmol})$ and sodium azide $(0.064 \mathrm{~g}, 1$ mmol) and the resulting solution was stirred at open air for 30 minutes. During this time, color changes to dark brown due to the partial oxidation of the manganese. Well-formed dark crystals were obtained after two days layering the solution with diethylether. Yield $70 \%$. Anal. calculated/found (\%) for complex 2, C, 36.4/36.7; H 4.1/4.0; N 19.6/19.7. 
The synthesis of the manganese complex $\mathbf{2}$ has been described starting from manganese formate but the same complex can be obtained starting from other manganese salts (nitrate, perchlorate or triflate) and in these cases, the formate anions were formed by catalytic oxidation of methanol, meaning that the final complex is extremely stable.

$\left[\mathrm{Ni}_{4}(\mathrm{L2})_{4}(\mathrm{MeOH})_{4}\right] \cdot \mathbf{2 M e O H}(\boldsymbol{S})-\mathbf{L 2},(3 S)$. A solution of $\mathrm{H}_{2} \mathrm{~L} 2(0.136 \mathrm{~g}, 0.5 \mathrm{mmol})$ and tryethylamine $(0.101 \mathrm{~g}, 1 \mathrm{mmol})$ dissolved in in $10 \mathrm{~mL}$ of methanol were mixed with nickel acetate tetrahydrate $(0.124 \mathrm{~g}, 0.5 \mathrm{mmol})$ previously dissolved in $10 \mathrm{~mL}$ of methanol. Slow evaporation gives well-formed green crystals after two weeks. Yield 60\%. Anal. calculated/found (\%) for complex 3S, C, 55.9/56.1; H 5.6/5.5; N 3.7/3.6.

$\left[\mathrm{Ni}_{2}(\mathrm{HL} 2)_{2}(\mathrm{HL} 4)\left(\mu_{11}-\mathrm{N}_{3}\right)\right] \cdot \mathbf{2 M e O H} \quad(R)-H L 2,(4 R),(S)-H L 2,(4 S)$. A solution of the corresponding $(R)-\mathrm{H}_{2} \mathrm{~L} 2$ or $(S)-\mathrm{H}_{2} \mathrm{~L} 2(0.136 \mathrm{~g}, 0.5 \mathrm{mmol})$ and tryethylamine $(0.101 \mathrm{~g}, 1 \mathrm{mmol})$ in $10 \mathrm{~mL}$ of methanol was mixed with nickel benzoate $(0.151 \mathrm{~g}, 0.5 \mathrm{mmol})$ previously dissolved in $10 \mathrm{~mL}$ of methanol. To this mixture was added sodium azido $(0.032 \mathrm{~g}, 0.5 \mathrm{mmol})$ dissolved in 5 $\mathrm{mL}$ of methanol. After some minutes an unidentified green solid was removed and X-Ray quality green crystals were obtained after one week by slow evaporation of the mother liquor. Yield 35\%. Anal. calculated/found (\%) for complex $4 \boldsymbol{R}$, C, 58.1/57.9; H 5.4/5.5; N 8.1/8.0 and 4S, C, 58.1/57.8; H 5.4/5.6; $\mathrm{N} 8.1 / 8.0$. The green precipitate obtained immediately after the mixing of the reagents was not identified but its IR spectrum shows the presence of $\mathrm{H}_{2} \mathrm{~L} 2$ ligands, benzoate and azido ligand. The cyclization of part of the ligands was probably produced during the crystallization. 


\section{RESULTS AND DISCUSSION}

Crystal Structure of $\left[\mathrm{Ni}_{2}\left(\mathrm{H}_{3} \mathrm{L3}\right)_{2}\left(\mu_{11}-\mathbf{N}_{3}\right)_{2} \mathrm{Cl}_{2}\right] \cdot 2 \mathrm{MeOH}$ (1). The centrosymmetric dinuclear complex consist of two nickel cations bridged by a double end-on azido bridge, two $\mathrm{H}_{3} \mathrm{~L} 3$ ligands and two chloro donors, Figure 1. Main bond parameters are summarized in Table 1. The $\mathrm{Ni}-\mathrm{N}-\mathrm{Ni}$ bond angle takes a value of $98.4^{\circ}$, which is in the usual range for the end-on azido bridges. ${ }^{24}$ The planar $\mathrm{Ni}_{2} \mathrm{~N}_{2}$ ring is practically symmetric with almost identical Ni-N bond distances. The octahedral coordination sphere of each cation is fulfilled with one $\mathrm{H}_{3} \mathrm{~L} 3$ ligand acting as a tridentate donor and one terminal choro ligand. The flexible $\mathrm{H}_{3} \mathrm{~L} 3$ ligand is coordinated in fac- mode by means of the $\mathrm{N}$-pyridinic, $\mathrm{N}$-oxazolidine and the $\mathrm{O}$-donor from one of the alkoxo arms.

Each protonated $\mathrm{O} 2$ donor establishes a strong H-bond with one of the chloro atoms of the neighbouring molecule with a $\mathrm{O} 2 \cdots \mathrm{Cl}$ distance of 3.069(3) $\AA$. The double intermolecular Hbonds determine the monodimensional arrangement of dimers in the network, Figure 1. The crystallization methanol molecules help to the stabilization of the molecule by means of two $\mathrm{H}-$ bonds with the uncoordinated alkoxo group (distance $\mathrm{O} 4 \cdots \mathrm{O} 3$ of $2.731 \AA$ ) and the chloro atom with $\mathrm{O} 4 \cdots$ Cl1 distance of $3.103 \AA$, Figure S2.

Despite of the precursor $\mathrm{H}_{3} \mathrm{~L} 1$ is achiral, the cyclization of the oxazolidine has as a consequence the generation of three chiral centres, placed on C6 and C7 carbons and on the prochiral protonated $\mathrm{N} 2$ atom. The chirality of these centres is $(R, S, S)$ for one of the ligands and $(S, R, R)$ for the second $\mathrm{H}_{3} \mathrm{~L} 3$ ligand which are related by one inversion centre placed in the middle of the molecule and thus, the complex should be assumed as a meso form. 

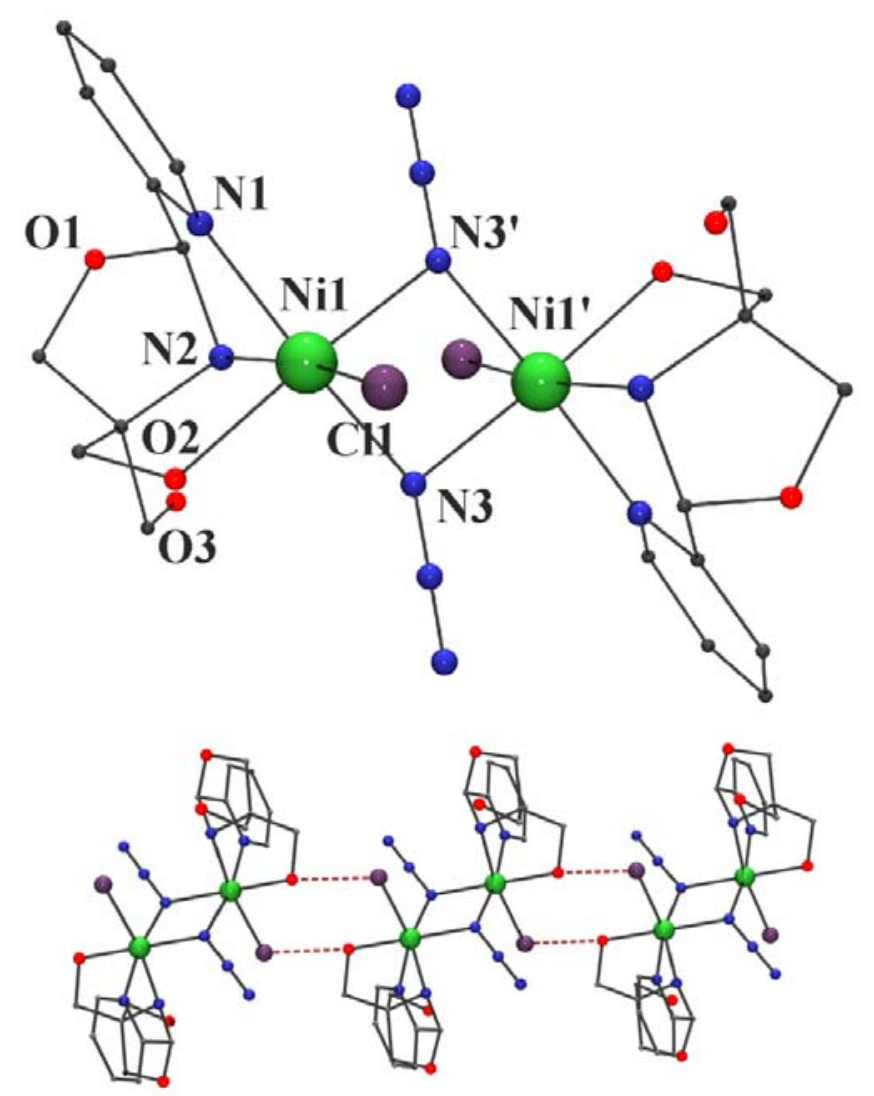

Figure 1. Top, labelled view of the dinuclear complex 1. Bottom, a view of the 1D arrangement of dimers linked by a double H-bond involving the chloro ligands and the coordinated alkoxo arm of $\mathrm{H}_{3} \mathrm{~L} 3$.

Table 1. Selected bond parameters for complex 1.

\begin{tabular}{|c|c|c|c|}
\hline Ni1-N1 & $2.088(3)$ & Ni1-N3-Ni1' & $98.4(1)$ \\
\hline Ni1-N2 & $2.087(3)$ & $\mathrm{O} 3 \cdots \mathrm{Cl} "$ & $3.069(3)$ \\
\hline Ni1-N3 & $2.100(3)$ & Ni1 $\cdots$ Ni2 & $3.1824(7)$ \\
\hline Ni-N3' & 2.104(3) & & \\
\hline Ni1-O2 & $2.097(3)$ & & \\
\hline $\mathrm{Ni1-Cl}$ & $2.389(1)$ & & \\
\hline
\end{tabular}




\section{Crystal Structure of $\left[\mathrm{Mn}_{6}{ }_{6} \mathrm{M}_{\mathrm{n}}{ }^{\mathrm{IV}}{ }_{2}(\mathrm{HL3})_{6}(\mathrm{HCOO})_{2}\left(\mathrm{~N}_{3}\right)_{4}\left(\mu_{11}-\mathrm{N}_{3}\right)\left(\mu_{13}-\mathrm{N}_{3}\right)\right] \cdot 3 \mathrm{MeOH} \cdot \mathrm{H}_{2} \mathrm{O}$ (2).}

The system consists of a chain of octanuclear clusters formed by two tetranuclear units linked by one end-on azido bridge placed on one $C_{2}$ axis that relates the two subunits, Figure 2. Main bond parameters are summarized in Table 2. The $\mathrm{Mn} 1, \mathrm{Mn} 3$ and $\mathrm{Mn} 4$ cations show a $\mathrm{MnN}_{4} \mathrm{O}_{2}$ or $\mathrm{MnN}_{3} \mathrm{O}_{3}$ environment with bond distances clearly larger than $2.1 \AA$, whereas the Mn2 cation exhibits a $\mathrm{MnO}_{6}$ octahedral coordination with bond distances shorter than $2.0 \AA$. In basis to the coordination environments, charge balance and BVS calculations (Table S3), the $\mathrm{Mn}^{\mathrm{II}}(\mathrm{Mn} 1$, $\mathrm{Mn} 3, \mathrm{Mn} 4)$ and $\mathrm{Mn}^{\mathrm{IV}}(\mathrm{Mn} 2)$ oxidation states were assigned. The octanuclear clusters are linked between them by end-to-end azido bridges that generate the 1D arrangement, Figure 2. Each tetranuclear subunit is formed by three divalent and one tetravalent manganese cations, three HL $3^{2-}$ ligands, two terminal azido ligands, one formate and the corresponding azido bridges. The $\mathrm{N}$-pyridinic and N-oxazolidine donors of the HL3 ${ }^{2-}$ ligands are coordinated to the divalent cations and the alkoxo arms of the ligand generate the $\mathrm{Mn}^{\mathrm{II}}-\mathrm{O}-\mathrm{Mn}^{\mathrm{IV}}$ bridges inside the cluster. Each one of the ligands shows a different coordination mode: the two alkoxo arms linked to Mn1 act as a bridge between one $\mathrm{Mn}^{\mathrm{II}}$ and the $\mathrm{Mn}^{\mathrm{IV}}$ cations, one alkoxo arm linked to $\mathrm{Mn} 3$ acts as a terminal ligand whereas the second alkoxo donor links Mn3 with the tetravalent Mn2 and finally, one alkoxo arm linked to Mn4 provides a bridge between Mn4 and Mn2 and the second arm gives a $\mu_{3}-\mathrm{O}$ donor placed in the triangular arrangement formed by Mn2, Mn3 and Mn4, Figure 3. The formate ligand is linked in its syn-syn coordination mode to the divalent Mn3 and Mn4 cations. The end-on azido bridge links the two moieties of the cluster with a Mn4-N13-Mn4' bond angle extremely large $\left(136.5^{\circ}\right)$ whereas the end-to-end azido bridges links the equivalent Mn1 cations from the next octanuclear unit with Mn1-N16-N17 bond angles of 139.5(2) ${ }^{\circ}$. 


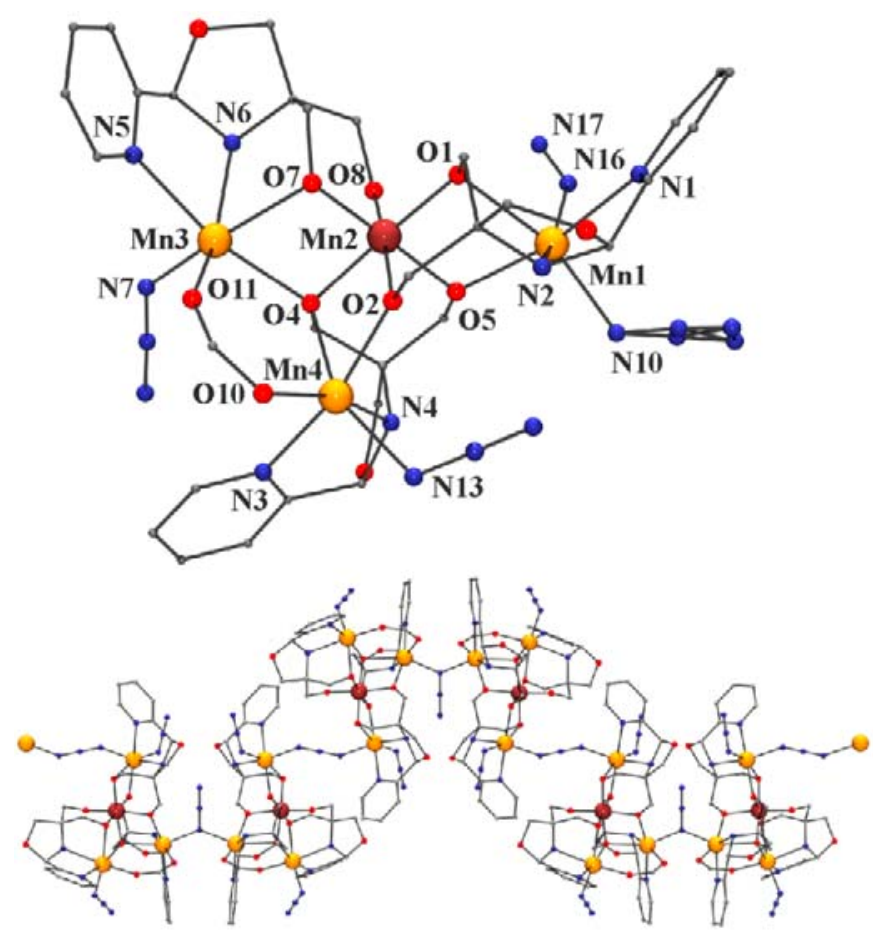

Figure 2. Top, labelled view of the asymmetric unit of complex 2. Bottom, a view of the 1D arrangement of the octanuclear $\left\{\mathrm{Mn}_{3}{ }_{3} \mathrm{Mn}^{\mathrm{IV}}-\left(\mu_{1,1}-\mathrm{N}_{3}\right)-\mathrm{Mn}_{3}{ }_{3} \mathrm{Mn}^{\mathrm{IV}}\right\}$ units linked by $\mu_{1,3}-\mathrm{N}_{3}$ bridges,

As in the previous case, the formation of the oxazolidine ring and its coordination to the cations generates three $\mathrm{CNC}$ chiral centres with $(R, R, S)$ configuration respectively. The presence of exclusively $C_{2}$ axis on the chain and the inter-chain reflection planes in the network determines that the chains are homochiral and that compound $\mathbf{2}$ is a racemic mixture of enantiopure chains. 

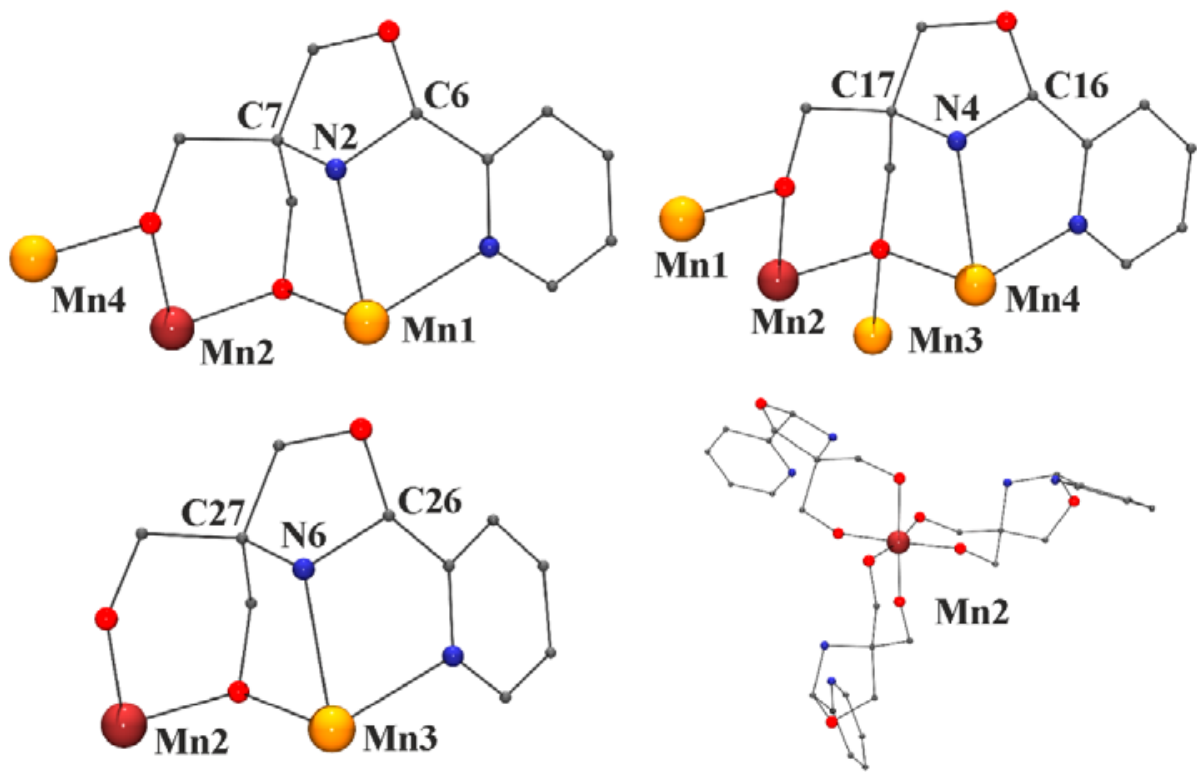

Figure 3. View of the different coordination modes of the $\mathrm{HL}^{2-}$ ligand and the cation environment for the manganese cations in complex 2. The labelled $\mathrm{C}$ and $\mathrm{N}$ atoms are those that become chiral centres.

Table 2. Selected bond parameters for complex 2.

\begin{tabular}{|l|l|l|l|}
\hline Mn1-N1 & $2.305(3)$ & Mn2-O1 & $1.885(2)$ \\
\hline Mn1-N2 & $2.307(2)$ & Mn2-O2 & $1.931(2)$ \\
\hline Mn1-N10 & $2.149(2)$ & Mn2-O4 & $1.960(2)$ \\
\hline Mn1-N16 & $2.162(2)$ & Mn2-O5 & $1.907(2)$ \\
\hline Mn1-O1 & $2.268(2)$ & Mn2-O7 & $1.889(2)$ \\
\hline Mn1-O5 & $2.152(2)$ & Mn2-O8 & $1.838(2)$ \\
\hline Mn3-N5 & $2.286(2)$ & Mn4-N3 & $2.249(2)$ \\
\hline Mn3-N6 & $2.319(2)$ & Mn4-N4 & $2.313(2)$ \\
\hline Mn3-N7 & $2.112(2)$ & Mn4-N13 & $2.224(1)$ \\
\hline
\end{tabular}




\begin{tabular}{|l|l|l|l|}
\hline Mn3-O4 & $2.245(2)$ & Mn4-O2 & $2.140(2)$ \\
\hline Mn3-O7 & $2.259(2)$ & Mn4-O4 & $2.273(2)$ \\
\hline Mn3-O11 & $2.122(2)$ & Mn4-O10 & $2.130(2)$ \\
\hline Mn2-O1-Mn1 & $98.13(7)$ & Mn3-O4-Mn4 & $113.17(7)$ \\
\hline Mn2-O5-Mn1 & $101.50(8)$ & Mn1-N16-N17 & $139.5(2)$ \\
\hline Mn2-O4-Mn3 & $97.94(7)$ & Mn4-N13-Mn4' & $136.5(2)$ \\
\hline Mn2-O7-Mn3 & $99.60(7)$ & & \\
\hline Mn2-O2-Mn4 & $104.72(7)$ & & \\
\hline Mn2-O4-Mn4 & $99.06(7)$ & & \\
\hline
\end{tabular}

Crystal Structure of $\left[\mathrm{Ni}_{4}(\mathrm{L2})_{4}(\mathrm{MeOH})_{4}\right] \cdot \mathrm{XMeOH}(3 S)$. The core of the structure of $3 S$ consist of a distorted $\left[\mathrm{Ni}_{4}\left(\mu_{3}-\mathrm{O}\right)_{4}\right]$ cubane core, in which the $\mu_{3}-\mathrm{O}$ corners are the $\mathrm{O}$-alkoxo atoms of the $\mathrm{L} 2^{2-}$ ligand. Each $\mathrm{L} 2^{2-}$ ligand coordinates one $\mathrm{Ni}^{\mathrm{II}}$ cation by means of the iminic nitrogen and the O-phenoxo donor. A partially labelled plot is shown in Figure 4 and the main bond parameters are summarized in Table 3 . The $\mathrm{NiNO}_{5}$ environment is fulfilled with one terminal $\mathrm{MeOH}$ ligand, which participates in intramolecular H-bonds with the $\mathrm{O}_{\text {phenoxo }}$ donors of the $\mathrm{L}^{2-}$ ligands $(\mathrm{O} \cdots \mathrm{O}$ distances: $2.62-2.74 \AA)$. Two opposite faces of the cube exhibit larger $\mathrm{Ni} \cdots \mathrm{Ni}$ separation and $\mathrm{Ni}-\mathrm{O}-\mathrm{Ni}$ bond angles (around $101^{\circ}$ ) than the other four faces. The coordination environment of the $\mathrm{Ni}^{\mathrm{II}}$ cations show a tetragonal elongation that involves the Ni-O bonds to the methanol molecules and the Ni-Oalkoxo placed in trans. The complex is asymmetric but the arrangement of the ligands is close to a pseudo- $\mathrm{S}_{4}$ symmetry. The structure is close to the related system obtained from the racemic mixture of ligands which contains a disordered mixing of enantiomers in the molecule. ${ }^{25}$ 

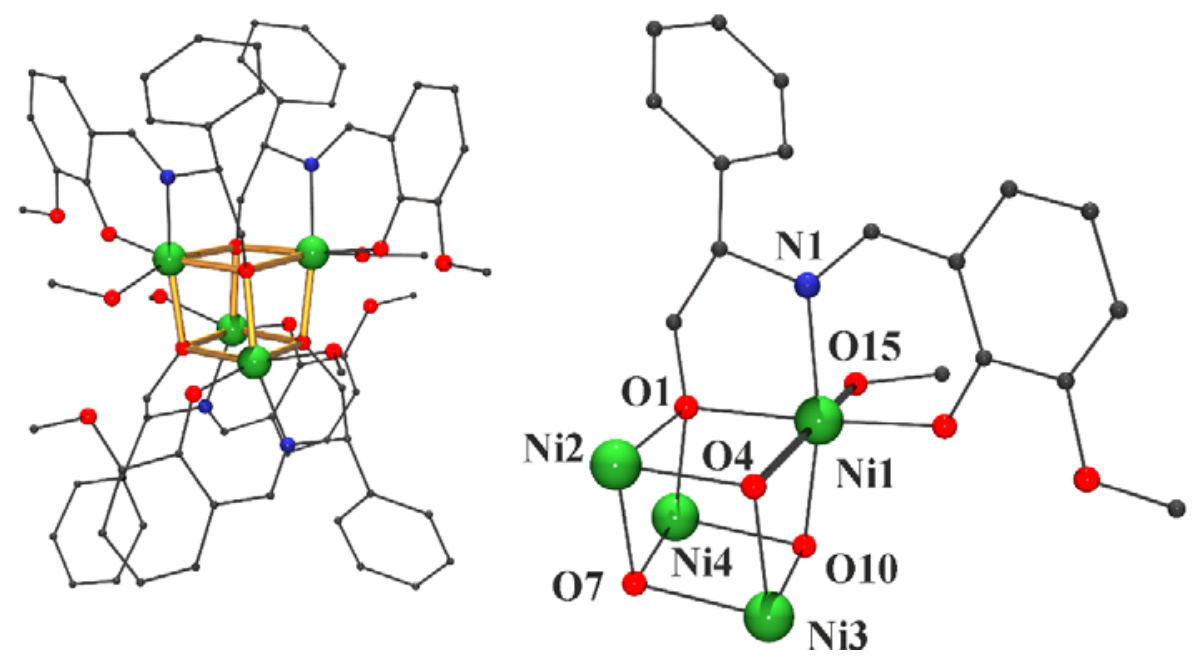

Figure 4. A view of the cubane structure of complex $3 S$ and its labelled core. The O4-Ni1-O15 direction corresponds to the elongated bonds.

Table 3. Selected bond parameters for complex $3 S$.

\begin{tabular}{|l|l|l|l|}
\hline Ni1-O1 & $2.018(8)$ & Ni3-O7 & $2.160(8)$ \\
\hline Ni1-O4 & $2.141(9)$ & Ni3-O10 & $2.034(8)$ \\
\hline Ni2-O1 & $2.122(8)$ & Ni4-O7 & $2.030(8)$ \\
\hline Ni2-O4 & $2.023(9)$ & Ni4-O10 & $2.150(8)$ \\
\hline Ni-O10 & $2.041(8)$ & Ni3-O4 & $2.020(9)$ \\
\hline Ni2-O7 & $2.064(8)$ & Ni4-O1 & $2.011(9)$ \\
\hline Ni1-O15 & $2.163(9)$ & & \\
\hline Ni1-O1-Ni2 & $101.7(3)$ & Ni3-O7-Ni4 & $99.6(3)$ \\
\hline Ni1-O4-Ni2 & $100.9(4)$ & Ni3-O10-Ni4 & $99.8(3)$ \\
\hline Ni1-O4-Ni3 & $94.1(4)$ & Ni2-O1-Ni4 & $94.6(3)$ \\
\hline Ni1-O10-Ni3 & $96.8(3)$ & Ni2-O7-Ni4 & $95.8(4)$ \\
\hline Ni1-O1-Ni4 & $98.4(4)$ & N2-O4-Ni3 & $99.2(4)$ \\
\hline Ni1-O10-Ni4 & $93.4(3)$ & Ni2-O7-Ni3 & $93.6(3)$ \\
\hline
\end{tabular}




\section{Crystal Structure of $\left[\mathrm{Ni}(\mathrm{HL2})_{2}(\mathrm{HL} 4)\left(\mu_{11}-\mathrm{N}_{3}\right)\right] \cdot 2 \mathrm{MeOH} \quad(R)-\mathrm{HL} 2,(4 R),(S)-\mathrm{HL2},(4 S)$.}

Shape and bond parameters for the two enantiomers are practically identical and thus a common description for both will be provided. The system consists of two $\mathrm{Ni}^{\mathrm{II}}$ cations, two monoanionic HL2 ligands, one monoanionic HL4- ligand and one end-on azido bridge, Figure 5. Main bond parameters are reported in Table 4. The HL2 ${ }^{-}$ligands act as tridentate donors and are mercoordinated to the $\mathrm{Ni}^{\mathrm{II}}$ cations. The HL4- ligand coordinates $\mathrm{Ni} 1$ and $\mathrm{Ni} 2$ cations employing the $\mathrm{O}_{\text {methoxide }}$ and the $\mathrm{N}_{\text {oxazolidine }}$ donors respectively, whereas the deprotonated $\mathrm{O}_{\text {phenoxo }}$ donor acts as a bridge with a Ni1-O5-Ni2 bond angle of $104.3^{\circ}$. The coordination environment of the cations is fulfilled with a $\mu_{11}-\mathrm{N}_{3}$ bridge with a Ni1-N4-Ni2 bond angle of $95.9^{\circ}$. The three oxazolidine chiral centers, generated after the coordination of $\mathrm{HL}^{-}$, show the $(R, S, R)$ configuration for $\mathrm{C} 17$, N2, C26 respectively for the complex obtained from $(R)-\mathrm{H}_{2} \mathrm{~L} 2(\mathbf{4 R})$ and the opposite $(S, R, S)$ configuration for the complex obtained from $(S)-\mathrm{H}_{2} \mathrm{~L} 2(4 S)$. All the relevant intermolecular contacts are H-bond interactions that involve the crystallization methanol molecules and the azido ligand $(\mathrm{O} 1 \mathrm{w} \cdots \mathrm{N} 6,2.959 \AA)$, the protonated alkoxo arm of one HL2- ligand $(\mathrm{O} 1 \cdots \mathrm{O} 1 \mathrm{w}$, $2.589 \AA)$ and the methoxo group of the second HL2- ligand (O1w $\cdots \mathrm{O} 8,2.866 \AA)$. 


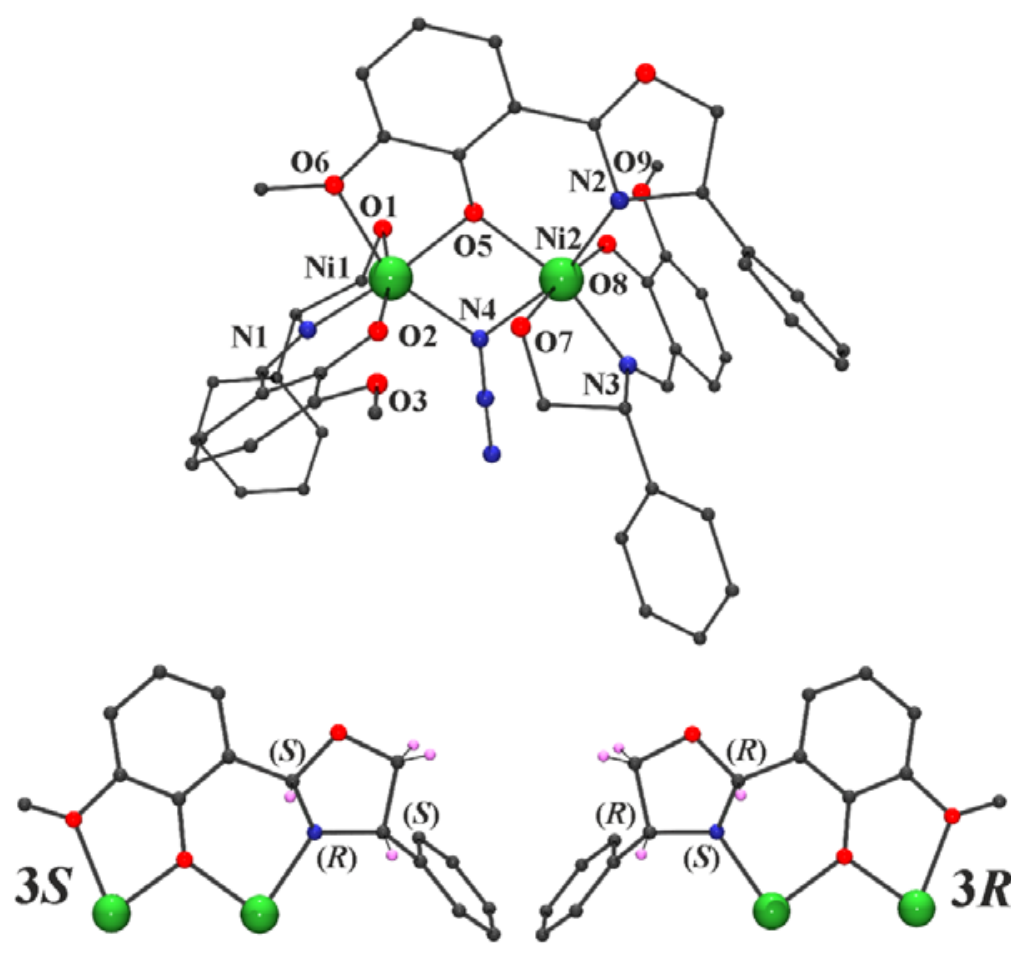

Figure 5. Top, a labeled view of the dinuclear complex 4 (labels are the same for $\mathbf{4 R}$ and $\mathbf{4 S}$ ). Bottom, mirror image of the chiral HL4- ligand indicating the chirality of each center for the two enantiomers.

Table 4. Selected bond parameters for complex $\mathbf{4 R}$. Bond parameters for the enantiomer $\mathbf{4 S}$ are practically identical.

\begin{tabular}{|l|l|l|l|}
\hline Ni1-O1 & $2.084(1)$ & Ni2-O5 & $2.017(1)$ \\
\hline Ni1-O2 & $1.999(2)$ & Ni2-O7 & $2.163(1)$ \\
\hline Ni1-O5 & $2.011(1)$ & Ni2-O8 & $2.012(1)$ \\
\hline Ni1-O6 & $2.187(2)$ & Ni2-N2 & $2.130(2)$ \\
\hline Ni1-N1 & $1.994(2)$ & Ni2-N3 & $1.995(2)$ \\
\hline Ni1-N4 & $2.100(2)$ & Ni2-N4 & $2.181(2)$ \\
\hline Ni1-O5-Ni2 & $104.26(6)$ & Ni1-N4-Ni2 & $95.91(7)$ \\
\hline
\end{tabular}




\section{Synthetic aspects}

Schiff bases like $\mathrm{H}_{3} \mathrm{~L} 1$, derived from the reactions among TRIS and pyridyl or quinolinealdehydes, linked to polyoxometallates or lanthanides with SMM response for the Dy case, have been recently characterized. ${ }^{26-28}$ However, $3 d$ complexes, containing cycled oxazolidines like $\mathrm{H}_{3} \mathrm{~L} 3$ instead the corresponding Schiff base, appears to be the most common reaction and some mononuclear $\mathrm{Cu}^{\mathrm{II}}$ or dinuclear $\mathrm{Fe}^{\mathrm{III}}$ compounds derived from the pyridyl ligands $s^{11-13}$ and several mononuclear or low nuclearity $3 d$ systems derived from the quinoline precursors $^{14-16}$ have also been reported. Formation of the oxazolidine ring requires the nucleophilic attack of one of the alkoxo arms on the iminic C-atom and the transfer of the proton to the $\mathrm{N}$-atom, Scheme 1. Most of the reported complexes have been prepared by the mixing of the aldehyde, TRIS and the metallic salt resulting the in situ cyclization of the Schiff base profiting the polarizing effect of the cation through the linkage to the iminic N-donor, that helps the nucleophilic attack of the alkoxo group and the formation of the heterocycle.

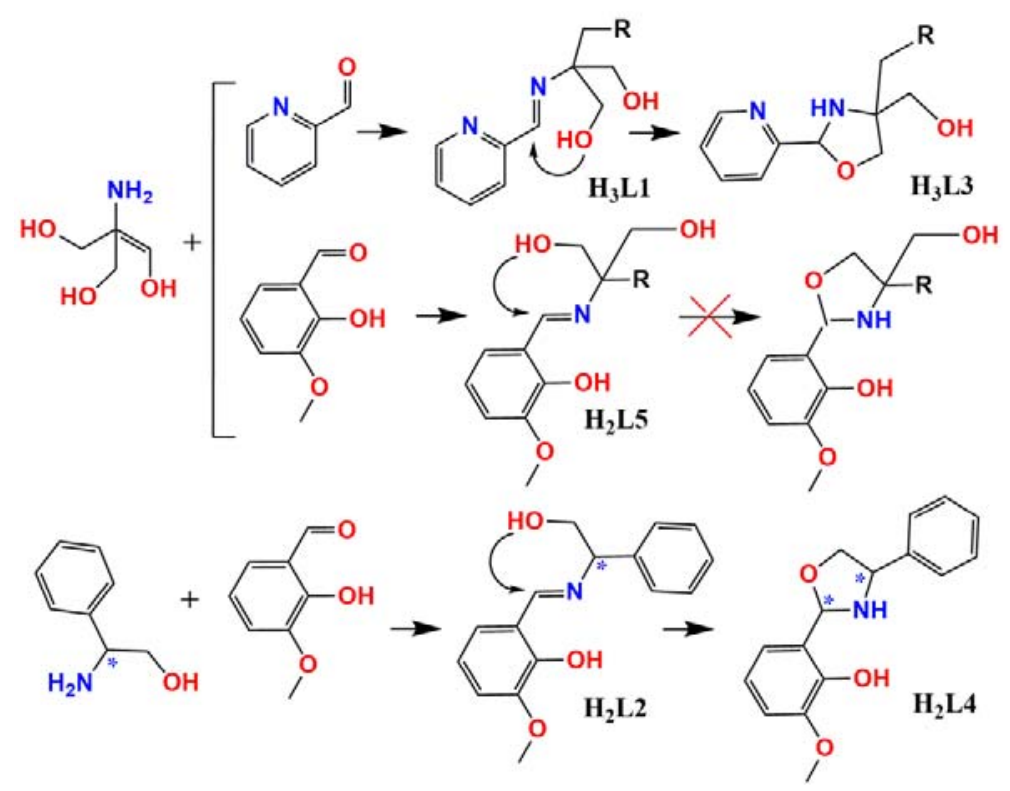


Scheme 1. Synthetic route that allows the oxazolidines $\mathrm{H}_{3} \mathrm{~L} 3$ and $\mathrm{H}_{3} \mathrm{~L} 4$. The reaction of TRIS with salicylaldehyde or $O$-vanillin always stops in the $\mathrm{H}_{3} \mathrm{~L} 5$ Schiff base and the derived oxazolidines were not previously reported.

In contrast with the easy formation of the oxazolidine containing N-heterocycles, the reaction is unfavourable for salicylaldehyde or $o$-vanillin precursors and as an example, the search in the CCDC database returns hundreds of complexes of ligands like $\mathrm{H}_{3} \mathrm{~L} 5$ (with substituted or not substituted $\mathrm{R}=\mathrm{H}, \mathrm{Me}, \mathrm{OH}$ aminoalcohol arms or from salicil or $\mathrm{o}$-vanillin precursors) but the corresponding oxazolidines derived from $\mathrm{H}_{3} \mathrm{~L} 5$ have not been never reported. In the same way, ligands like $\mathrm{H}_{2} \mathrm{~L} 4$, present in complexes $\mathbf{4 R}$ and $\mathbf{4 S}$, are unprecedented. The only two related phenol-oxazolidine derivatives have been reported starting from 2,6-diformyl-4-methylphenol ${ }^{29}$ or from the reaction of salicylaldehyde with 3-aminopropane-1,2-diol, that yields either oxazinanes and oxazolidines. ${ }^{30}$ One factor that becomes crucial in well studied ligands as could be the diol derivatives of dipyridyl ketone, ${ }^{31}$ is the presence of pyridinic rings that helps to polarize the iminic group helping the nucleophilic attack. Noteworthy, there is not a clear reason to justify the cyclization of $\mathrm{H}_{2} \mathrm{~L} 2$ if we compare the syntheses of compounds 3 and $\mathbf{4}$ or the previously reported complex $\left[\mathrm{Ni}_{4}(\mathrm{~L} 2)\left(\mathrm{N}_{3}\right)_{2} \mathrm{Cl}_{2}(\mathrm{MeOH})_{2}\right]$ which were obtained in similar conditions $\mathrm{s}^{32}$ with a common stoichiometry, solvent or basic medium and only changing the anion chloride vs. benzoate in the case of complexes $\mathbf{4 R} / \mathbf{4 S}$.

Noteworthy, one of the most interesting features is that starting of enantiomerically pure chiral precursors like $(R)$ - or $(S)$-phenylglycinol, the chirality is transferred to the final compound, allowing to the selective syntheses of the corresponding oxazolidines with $(R, S, R)$ or $(S, R, S)$ configuration for the $\mathrm{C}, \mathrm{N}, \mathrm{C}$ atoms respectively. Chiral complexes derived from other 
oxazilidines proved to be interesting antitumoral agents. ${ }^{4,5}$ For this reason catalytic cyclization of Schiff bases like $\mathrm{H}_{2} \mathrm{~L} 2$ becomes an interesting source of new complexes.

\section{Electronic Circular Dichroism}

Electronic Circular Dichroism (ECD) spectra were recorded for the enantiomeric pair $\mathbf{4 R}$ and 4S, which contain the chiral ligands $\mathrm{HL}^{-}$and $\mathrm{HL}^{-}$with one and three chiral centers respectively. $\mathbf{4 R}$ exhibits positive Cotton effect at 214, 260 and $388 \mathrm{~nm}$ and negative peaks at 238, $285 \mathrm{~nm}$, vanishing the absorptions for larger wavelengths and $\mathbf{4 S}$ shows exactly the mirrorimage spectrum, Figure 6. Comparison with the previously reported spectra for related complexes derived from $\mathrm{H}_{2} \mathrm{~L} 2$ shows the characteristic high energy absorptions below $300 \mathrm{~nm}$ due to the $\pi-\pi^{*}$ transitions of the aromatic groups of the ligands whereas the absorptions above this wavelength are attributable to absorptions related with the chiral cationic centers. ${ }^{33-35}$

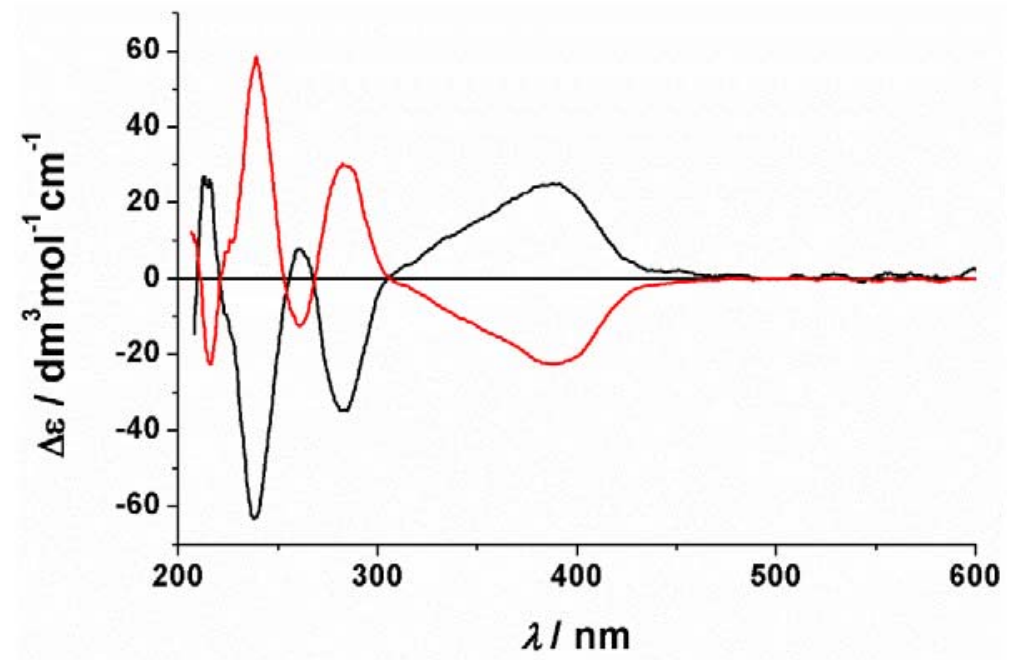

Figure 6. ECD spectra showing the mirror-image absorptions for complexes $\mathbf{4 R}$ (red line) and $4 S$ (black line). 


\section{Magnetic study.}

The $\chi_{M} T$ value at room temperature for the two dinuclear complexes $\mathbf{1}$ and $\mathbf{4}$ are 2.90 and 2.64 $\mathrm{cm}^{3} \cdot \mathrm{mol}^{-1} \cdot \mathrm{K}$ respectively, larger than the expected value for two non-interacting $S=1$ spins $(\mathrm{g}=$ 2.00). On cooling, the plots reach a maximum value of $3.39 \mathrm{~cm}^{3} \cdot \mathrm{mol}^{-1} \cdot \mathrm{K}$ at $45 \mathrm{~K}(\mathbf{1})$ and 3.56 $\mathrm{cm}^{3} \cdot \mathrm{mol}^{-1} \cdot \mathrm{K}$ at $17 \mathrm{~K}(4)$ and below the maxima strongly decreases down to $0.73 \mathrm{~cm}^{3} \cdot \mathrm{mol}^{-1} \cdot \mathrm{K}$ at $2 \mathrm{~K}$ for 1 whereas the decrease is moderate for 4 , reaching $2.71 \mathrm{~cm}^{3} \cdot \mathrm{mol}^{-1} \cdot \mathrm{K}$ at $2 \mathrm{~K}$, Figure 7 , top. This response evidences intramolecular ferromagnetic response and a very different anisotropic behavior or intermolecular interactions at low temperature.

In light of the structural data for 1, that show strong intermolecular interactions, Figure 1, and that $D$ and z'J' parameters are always strongly correlated, the system was simulated by means of the isotropic $H=-2 J\left(S_{1} \cdot S_{2}\right)$ Hamiltonian, attributing the low temperature decay of $\chi_{M} T$ to the intermolecular interactions parametrized with the inclusion of the $z^{\prime} J$ ' term. Best fit parameters were $J=11.9(7) \mathrm{cm}^{-1}, g=2.27(1)$ and $z^{\prime} J^{\prime}=-0.45 \mathrm{~cm}^{-1}$. The strong effect of the intermolecular interactions is reflected in the magnetization measurements: the isothermal measurement at $2 \mathrm{~K}$ shows a sigmoid shape with inflexion point around $2.5 \mathrm{~T}\left(\sim 2.5 \mathrm{~cm}^{-1}\right)$ reaching only $3.6 \mathrm{MN}_{\beta}$ under the maximum field of $5 \mathrm{~T}$, Figure 7, inset. Reduced magnetization measurements also confirm the strong intermolecular interactions and are not useful to extract information about the $D$ parameter even employing only the higher field data, Figure 8.

The structure of $\mathbf{4}$ shows weak intermolecular interactions and thus the data for $\mathbf{4}$ was fitted employing the same Hamiltonian but including a $D$ term to simulate the $\chi_{M T}$ decay at low temperature. Simultaneous fit of the susceptibility and isothermal magnetization at $2 \mathrm{~K}$ yielded the best fit parameters $J=+13.53(1) \mathrm{cm}^{-1}, g=2.204(1)$ and $D_{\text {ion }}=-1.94 \mathrm{~cm}^{-1}$. The dominant 
effect of $D$ at low temperature was confirmed by the fit of the reduced magnetization as a well isolated $S=2$ ground state, resulting the best fit values of $D_{S=2}=-1.79(2) \mathrm{cm}^{-1}$ for a $g=2.192(1)$, Figure 8.
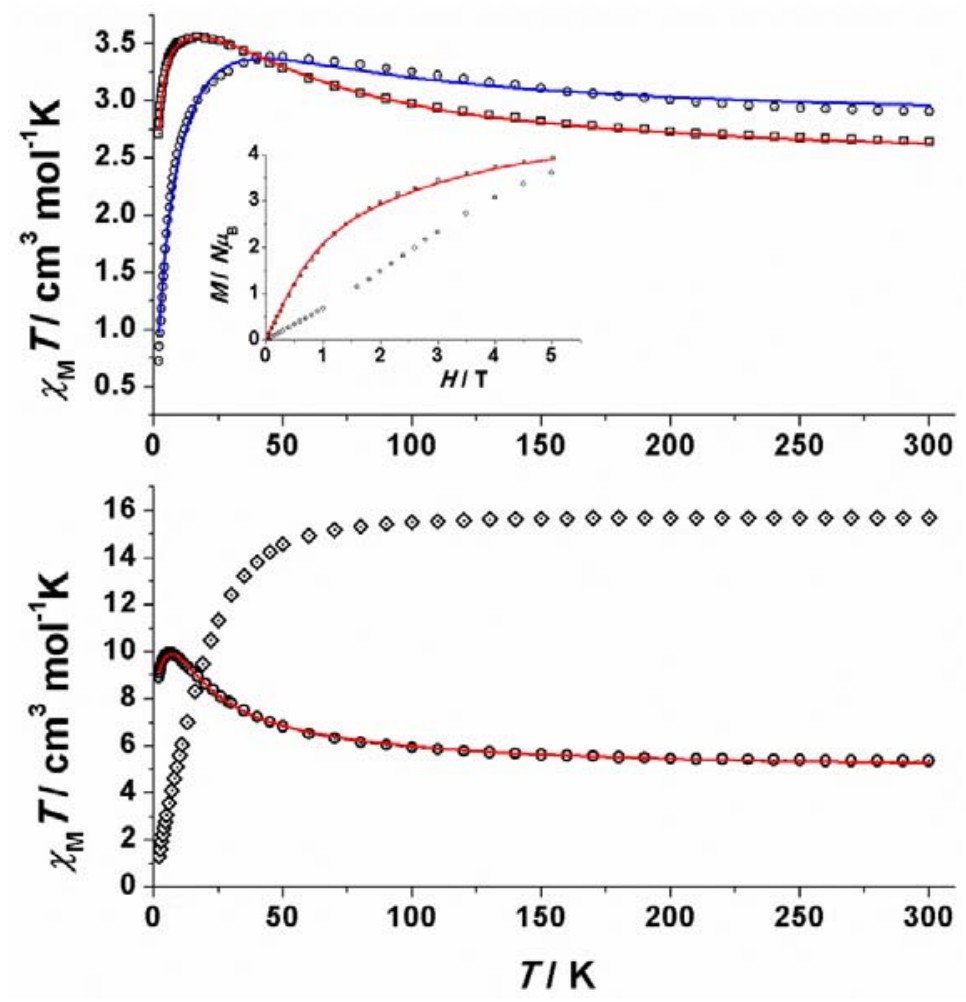

Figure 7. Top, $\chi_{M} T$ plots for the dinuclear complexes 1 (circles) and 4 (squares). Inset magnetization plot for $\mathbf{1}$ and $\mathbf{4}$. Bottom, $\chi_{M} T$ plots for compounds $\mathbf{2}$ (diamonds) and $\mathbf{3}$ (circles). Solid lines show the best fit of the experimental data. 


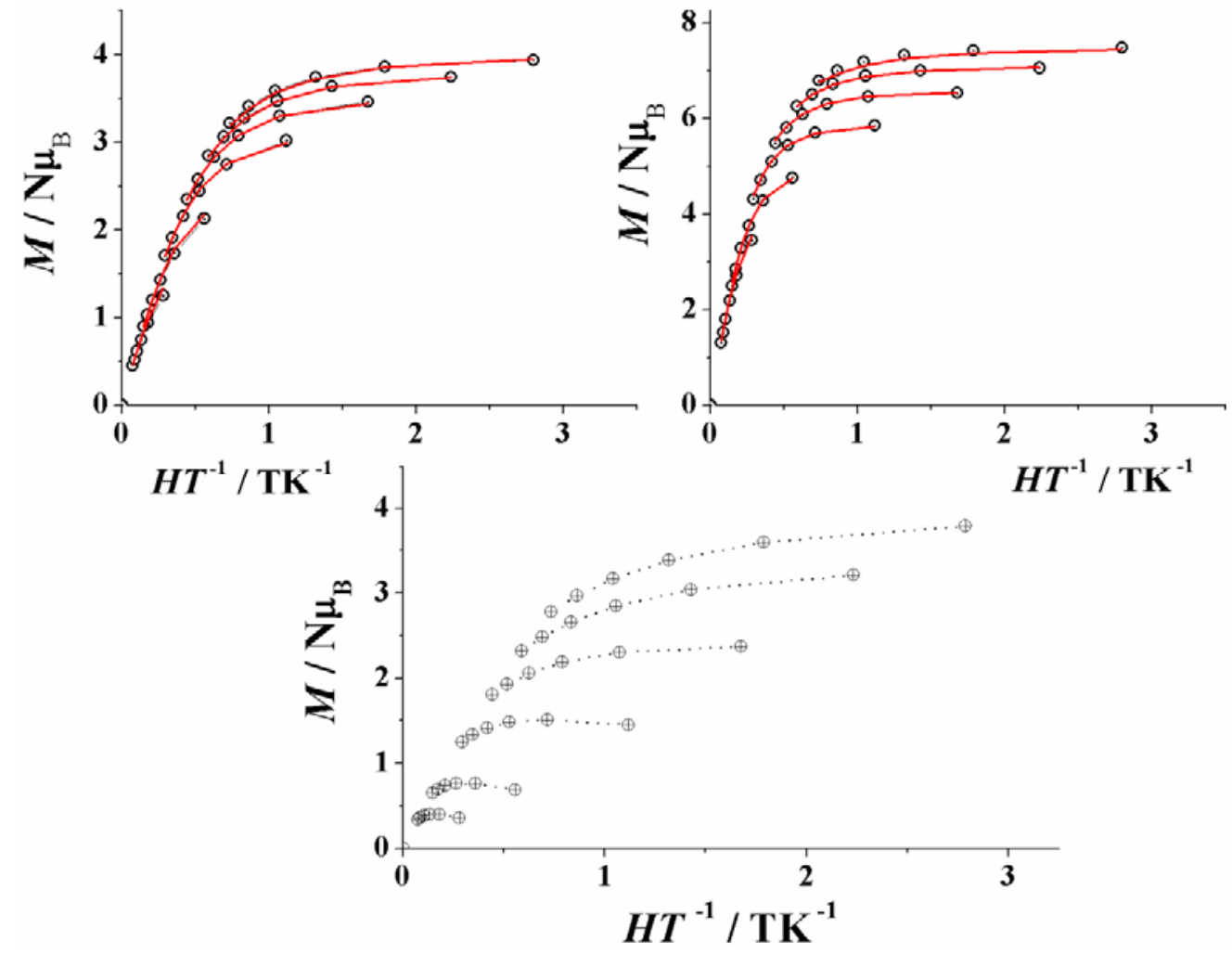

Figure 8. Top, reduced magnetization plots between $1.8-6.8 \mathrm{~K}$ with $1 \mathrm{~K}$ increment for the dinuclear complex 4 (left) and the cubane cluster 3 (right). Solid lines show the best fit of the experimental data. Bottom, reduced magnetization for the dinuclear complex 1. Dotted line is an eye-guide.

The $\chi_{M} T$ value at room temperature for the cubane complex 3 is $5.28 \mathrm{~cm}^{3} \cdot \mathrm{mol}^{-1} \cdot \mathrm{K}$, larger than the expected $4.00 \mathrm{~cm}^{3} \cdot \mathrm{mol}^{-1} \cdot \mathrm{K}$ value for four isolated $S=1$ spins (Figure 7, bottom). On cooling the $\chi_{M} T$ value increases up to a maximum value of $9.95 \mathrm{~cm}^{3} \cdot \mathrm{mol}^{-1} \cdot \mathrm{K}$ at $7 \mathrm{~K}$, followed by a decay down to $8.90 \mathrm{~cm}^{3} \cdot \mathrm{mol}^{-1} \cdot \mathrm{K}$ at $7 \mathrm{~K}$, suggesting a dominant ferromagnetic intramolecular interaction. In light of the $2+4$ shape of the cubano faces, fit of the experimental data was performed according the coupling scheme reported in Figure S3 and applying the derived $2 J$ Hamiltonian: 


$$
\mathrm{H}=-2 J_{1}\left(S_{1} \cdot S_{2}+S_{3} \cdot S_{4}\right)-2 J_{2}\left(S_{1} \cdot S_{3}+S_{1} \cdot S_{4}+S_{2} \cdot S_{3}+S_{2} \cdot S_{4}\right)
$$

and in light of the weak intermolecular interactions found in its structure, simulating the low $\mathrm{T}$ decay by means of the inclusion of a $D$ term. Best fit parameters were $J_{1}=-14.8(1) \mathrm{cm}^{-1}, J_{2}=$ $+23.0(1) \mathrm{cm}^{-1}, g=2.070(2)$ and $D_{\text {ion }}=-1.29(4) \mathrm{cm}^{-1}$. The sign of the coupling constants shows a good agreement with the well stablished correlations for distorted cubane structures based on the Ni-O-NI bond angles, that has ferro-antiferromagnetic border around $98^{\circ}$ and increasing antiferromagnetic interactions for larger bond angles. ${ }^{36-39}$

Magnetization measurements show a saturation value of $7.45 \mathrm{MN}_{\beta}$ under a field of $5 \mathrm{~T}$ clearly lower than the expected for an $S=4$ spin. To determine the $D$ parameter, reduced magnetization measurements were performed and fitted as an isolated $S=4$ spin level, yielding the best fit values of $D_{S=4}=-0.72(1) \mathrm{cm}^{-1}$ and $g=2.06$. From these data that give a $D S^{2}$ value $\sim 11 \mathrm{~cm}^{-1}$ and a possible SMM response, alternate current measurements were performed but, as has been reported for cubane systems with related Schiff bases, ${ }^{40}$ no out-of-phase response was observed. The high value of $D$ is consequence of the tetragonal elongation of the coordination polyhedron around the nickel cations but the unfavorable arrangement of the easy axis that are perpendicular between them (close to $S_{4}$ symmetry, Figure 4) and the strong tunneling excludes the out-ofphase signals even under transverse fields.

The $\chi_{M} T$ value at room temperature for complex 2 is $15.7 \mathrm{~cm}^{3} \cdot \mathrm{mol}^{-1} \cdot \mathrm{K}$ by tetranuclear unit, close to the expected value of $15.0 \mathrm{~cm}^{3} \cdot \mathrm{mol}^{-1} \cdot \mathrm{K}$ for three $S=5 / 2$ and one $S=3 / 2$ non interacting ligands assuming $g=2.00$. On cooling the $\chi_{M} T$ value remains practically constant in the $300-70$ $\mathrm{K}$ range and below this temperature it shows a continuous decay down to $1.31 \mathrm{~cm}^{3} \cdot \mathrm{mol}^{-1} \cdot \mathrm{K}$ at 2 K, Figure 7, bottom. The shape of the susceptibility plot and the large number of superexchange 
pathways excludes trials to fit the experimental data, even as an approach to the tetranuclear unit at medium-high temperatures. However, on one hand, in light of the structural features and the previously reported magneto-structural correlations it is possible to rationalize the overall response of the system. The superexchange pathways inside the tetranuclear fragments are six $\mathrm{Mn}^{\mathrm{II}}-\mathrm{O}-\mathrm{Mn}^{\mathrm{IV}}$ bridges and only one $\mathrm{Mn}^{\mathrm{II}}-\mathrm{O}-\mathrm{Mn}^{\mathrm{II}}$ interaction which, with a Mn3-O4-Mn4 bond angle of $113.17^{\circ}$, should be assumed as usual as weakly antiferromagnetic. The scarce number of $\mathrm{Mn}^{\mathrm{II}} \mathrm{Mn}^{\mathrm{IV}}$ measured systems ${ }^{41-47}$ was recently summarized by Christou et al. ${ }^{48}$ but any correlation or general rule was extracted for the $\mathrm{Mn}^{\mathrm{II}}-\mathrm{O}-\mathrm{Mn}^{\mathrm{IV}}$ pathway. The only empirical feature was that the interaction is usually weak, being ferro- or antiferromagnetic as function of the kind of bridge and topology. The flat $\chi_{M} T$ value in a wide range of temperature suggest weak ferroantiferromagnetic interactions inside the tetranuclear unit, with a probable antiferromagnetic interaction between divalent manganese cations $\mathrm{Mn} 3$ and $\mathrm{Mn} 4$ and weak ferromagnetic interactions between the divalent and tetravalent cations. End-to-end azido bridges between $\mathrm{Mn}^{\mathrm{II}}$ cations with $180^{\circ} \mathrm{Mn}-\mathrm{NNN}-\mathrm{Mn}$ torsion angles and $\mathrm{Mn}-\mathrm{N}-\mathrm{N}$ bond angles around $140^{\circ}$ give moderately strong antiferromagnetic coupling. ${ }^{24}$ On the other hand, it is well stablished that endon azido bridges usually gives ferromagnetic interactions for low bond angles but the coupling diminishes for very large angles like those found in complex 2 (Mn-N-Mn 136.5 ${ }^{\circ}$. However, independently of the interactions or local spin inside each tetranuclear fragment, the antiferromagnetic interactions, mediated by the end-to-end azido bridges must allow a dominant antiferromagnetic response with an $S=0$ ground state. The magnetization measurements show a sigmoid shape with inflexion point around $2 \mathrm{~T}\left(\sim 2 \mathrm{~cm}^{-1}\right)$ that could be attributed to the weaker intercluster interaction mediated by the end-on azido bridge. As is expected for an 
antiferromagnetic system, the magnetization value of $6.2 \mathrm{MN}_{\beta}$ under the maximum field of $5 \mathrm{~T}$ is far from the saturation.

\section{CONCLUSIONS}

Series of new $\mathrm{Ni}^{\mathrm{II}}$ and mixed valent $\mathrm{Mn}^{\mathrm{II}} \mathrm{Mn}^{\mathrm{IV}}$ complexes containing oxazolidine/azido ligands have been characterized. The different reactivity of the pyridyl and phenolic precursors has been compared and one unprecedented oxazolidine-derived complex obtained by metal assisted cyclization of (2-hydroxy-1-phenylethyl)imino)methyl)-6-methoxyphenolato $\left(\mathrm{H}_{2} \mathrm{~L} 2\right)$ has been characterized. Transfer of chirality from the enantiomerically pure phenylglycinol precursors allowed to the corresponding $(R, S, R)$ and $(S, R, S)$ chiral oxazolidines. The systems have been magnetically characterized, showing a ferromagnetic response for the $\mathrm{Ni}^{\mathrm{II}}$ systems $\mathbf{1}, \mathbf{3}$ and $\mathbf{4}$ and overall antiferromagnetic response for the $\mathrm{Mn}^{\mathrm{II}} \mathrm{Mn}^{\mathrm{IV}}$ complex 2 .

\section{ASSOCIATED CONTENT}

\section{Supporting Information.}

Crystal data, collection details, IR spectra for complexes 1-4 and BVS calculations for 2 can be found in Tables S1-S3 and Figures S1-S3. 


\section{Accession Codes}

CCDC 1993842 (1), 1993843 (2), 1993844 (3), 1993845 (4R) and 1993846 (4S) contain the supplementary crystallographic data for this paper. These data can be obtained free of charge via www.ccdc.cam.ac.uk/data_request/cif.

\section{AUTHOR INFORMATION}

\section{Corresponding Author}

* E-mail: albert.escuer@ub.edu; http://www.ub.edu/inorgani/recerca/MagMol/magmol.htm

\section{Author Contributions}

The manuscript was written through contributions of all authors.

\section{Funding Sources}

Ministerio de Economia y Competitividad (Spain), Project PGC2018-094031-B-100.

\section{ACKNOWLEDGMENT}

Financial support from Ministerio de Economia y Competitividad (Spain), Project PGC2018094031-B-100 is acknowledged.

\section{REFERENCES}

(1) Mikami, K. New frontiers in asymmetric catalysis. Wiley-VCH, 2007.

(2) Liu, X.; Manzur, C.; Novoa, N.; Celedón, S.; Hamon, J. R. Multidentate unsymmetricallysubstituted Schiff bases and their metal complexes: synthesis, functional materials properties, and applications to catalysis. Coord. Chem. Rev. 2018, 357, 144-172. 
(3) Andruh, M. The exceptionally rich coordination chemistry generated by Schiff-base ligands derived from o-vanillin. Dalton Trans. 2015, 44, 16633-16653.

(4) Lee, K. Y.; Ng, Y. L.; Wang, W. S.; Ng, P. Y.; Chan, C. W.; Lai, J. W.; Davamani, F.; Chitra, E.; Lim, W. M.; Ganguly, R.; Maah, M. J.; Yip F. W.; Ng C. H. Enantiomeric pairs of ternary copper(ii) complexes and their aldol-type condensation products: synthesis, characterization, and anticancer and epigenetic properties. Dalton Trans. 2019, 48, 4987-4999.

(5) Ng, C. H.; Wang, W. S.; Chong, K. V.; Win, Y. F.; Neo, K. E.; Lee, H. B.; San, S. L.; Abd. Rahmand, R. N. Z. R.; Leong, W. K. Ternary copper(ii)-polypyridyl enantiomers: aldol-type condensation, characterization, DNA-binding recognition, BSA-binding and anticancer property. Dalton Trans. 2013, 42, 10233-10243.

(6) Wolf, C.; Liu, S. Bisoxazolidine-catalyzed enantioselective alkynylation of aldehydes. J. Am. Chem. Soc. 2006, 128, 10996-10997.

(7) Wolf, C.; Xu, H. Asymmetric catalysis with chiral oxazolidine ligands. Chem. Commun. 2011, 47, 3339-3350.

(8) Wolf, C.; Zhang, P. Asymmetric Friedel-Crafts reaction of indoles with ethyl trifluoropyruvate using a copper(I)-bisoxazolidine catalyst. Adv. Synth. Catal. 2011, 353, 760766.

(9) Nakano, H.; Okuyama, Y.; Takeshita, M.; Kwon, E.; Kohari, Y.; Matsuyama, H. Development of asymmetric reactions using chiral oxazolidine-type catalysts. J. Synth. Org. Chem. 2012, 70, 142-153. 
(10) Ardizzoia, G. A.; Brenna, S.; Therrien, B. Ni(ii) and Pd(ii) pyridinyloxazolidinecompounds: synthesis, X-ray characterisation and catalytic activities in the aza-Michael reaction. Dalton Trans. 2012, 41, 783-790.

(11) Canabarro, C. M.; Ceolin, J.; Siqueira, J. D.; Iglesias, B. A.; de Oliveira, G. M.; Back, D. F.; Campos, P. T. Evaluation of the antioxidant activity of copper(II) complexes containing tris(hydroxymethyl)aminomethane (TRIS) units. Z. Anorg. Allg. Chem. 2016, 642, 1192-1197.

(12) Bikas, R.; Ajormal, F.; Emami, M.; Sanchiz, J.; Noshiranzadeh, N.; Kozakiewicz, A. Crystal structure and magneto-structural investigation of alkoxido bridged dinuclear Fe(III) complexes with 1,3-oxazolidine ligands. Polyhedron 2019, 162, 20-29.

(13) Bikas, R.; Ajormal, F.; Emami, M.; Noshiranzadeh, N.; Kozakiewicz, A. Catalytic oxidation of benzyl alcohols by new $\mathrm{Cu}$ (II) complexes of 1,3-oxazolidine based ligand obtained from a solvent free reaction. Inorg. Chim. Acta 2018, 478, 77-87.

(14) Ceolin, J.; Siqueira, J. D.; Martins, F. M.; Piquini, P. C.; Iglesias, B. A.; Back, D. F.; de Oliveira, G. M. Oxazolidine copper complexes: synthesis, characterization and superoxide dismutase activity of copper(II) complexes with oxazolidine ligands derived from hydroxyquinoline carboxaldehyde. Appl. Organomet. Chem. 2018, 32, e4218.

(15) Saleem, A.; Kobielska, P. A.; Harms, K.; Katsikogianni, M. G.; Telford, R.; Novitchi, G.; Nayak, S. Transition metal complexes of a versatile polyalkoxy oxazolidine-based ligand derived from in situ cyclization. Dalton Trans. 2018, 47, 6156-6165.

(16) Kobielska, P. A.; Telford, R.; Rowlandson, J.; Tian, M.; Shahin, Z.; Demessence, A.; Ting, V. P.; Nayak, S. Polynuclear complexes as precursor templates for hierarchical 
microporous graphitic carbon: an unusual approach. ACS Applied Materials and Interfaces 2018, 10, 25967-25971.

(17) a) Escuer, A.; Mayans, J.; Font-Bardia, M.; Górecki M.; Di Bari, L. Syntheses, structures, chiroptical and magnetic properties of chiral clusters built from Schiff bases: a novel $\left[\mathrm{Mn}^{\mathrm{II}} \mathrm{Mn}^{\mathrm{III}}{ }_{6} \mathrm{Na}_{2}{ }_{2}\right]$ core. Dalton Trans. 2017, 46, 6514-6517.

(18) Escuer, A.; Mayans, J.; Font-Bardia, M.; Di Bari, L.; Górecki, M. Mn3 ${ }^{\mathrm{III}}$ complexes derived from R/S-Schiff bases: chiral Single-Molecule-Magnets. Eur. J. Inorg. Chem. 2017, 991998.

(19) Mayans, J.; Font-Bardia, M.; Di Bari, L.; Escuer, A. Chiral $\left[\mathrm{Mn}^{\mathrm{II}}{ }_{2} \mathrm{Mn}^{\mathrm{III}}{ }_{6} \mathrm{M}\right]\left(\mathrm{M}=\mathrm{Na}^{\mathrm{I}}, \mathrm{Ca}^{\mathrm{II}}\right.$, $\left.\mathrm{Mn}^{\mathrm{II}}\right]$ and $\left[\mathrm{Mn}^{\mathrm{II}}{ }_{2} \mathrm{Mn}^{\mathrm{III}}{ }_{6} \mathrm{Na}_{2}{ }_{2}\right]$ clusters built from an enantiomerically pure Schiff base: synthetic, chiroptical and magnetic properties. Chem. Eur. J. 2018, 24, 18705-18717.

(20) Mayans, J.; Font-Bardia, M.; Escuer, A. Triple halide bridges in chiral $\mathrm{Mn}_{2}{ }_{2} \mathrm{Mn}^{\mathrm{III}}{ }_{6} \mathrm{Na}_{2}{ }_{2}$ cages: structural and magnetic characterization. Inorg. Chem. 2018, 57, 926-929.

(21) Chilton, N. F.; Anderson, R. P.; Turner, L. D.; Soncini, A.; Murray, K. S. PHI: a powerful new program for the analysis of anisotropic monomeric and exchange-coupled polynuclear dand f-block complexes. J. Comput. Chem. 2013, 34, 1164-1165.

(22) Sheldrick, G. M. A short history of SHELX. Acta Crystallogr. Sect A: Fundam. Crystallogr. 2008, 64, 112-122.

(23) Farrugia, L. J. ORTEP-3 for Windows - a version of ORTEP-III with a graphical user interface (GUI). J. Appl. Crystallogr. 1997, 30, 565. 
(24) Escuer, A.; Esteban, J.; Perlepes, S. P.; Stamatatos, T. C. The bridging azido ligand as a central "player" in high-nuclearity 3d-metal cluster chemistry. Coord. Chem. Rev. 2014, 275, 87129.

(25) Lian, Q. Y.; Hu, H. N.; Li, C. H.; Li, D. P.; Jiao, X. Y.; Li, Y. X. A new tetranuclear cubane-like Ni(II) complex based on Schiff-base ligand: Synthesis, crystal structure and magnetic properties. Chin. J. Struct. Chem. 2017, 36, 273-279.

(26) Nachtigall, O.; Spandl, J. Versatile organic chemistry on vanadium-based multi-electron reservoirs. Chem. Eur. J. 2018, 24, 2785-2789.

(27) Marcoux, P. R.; Hasenknopf, B.; Vaissermann, J.; Gouzerh, P. Developing remote metal binding sites in heteropolymolybdates. Eur. J. Inorg. Chem. 2003, 2406-2412.

(28) Zhang, M.; Li, H.; Chen, P.; Sun, W.; Zhang, L.; Yan, P. Self-assembly of 2-aldehyde-8hydroxyquinolinate-based lanthanide complexes and NIR luminescence. J. Mol. Struct. 2015, $1081,233-236$.

(29) Lin, S. Y.; Li, X. L.; Ke, H.; Xu, Z. A series of tetranuclear lanthanide compounds constructed by in situ polydentate ligands: synthesis, structure, and SMM behaviour of the Dy4 compound. CrystEngComm 2015, 17, 9167-9174.

(30) Ding, C.; Zeng, F.; Ni, J.; Wang, B.; Xie, Y. Polynuclear complexes of ligands containing in situ formed oxazinane and oxazolidine rings with appended alkoxyl and phenol groups. Cryst. Growth Des. 2012, 12, 2089-2096.

(31) Stamatatos, T. C.; Efthymiou, C. G.; Stoumpos C. C.; Perlepes, S. P. Adventures in the coordination chemistry of di-2-pyridyl ketone and related ligands: from high-spin molecules and 
Single-Molecule Magnets to coordination polymers, and from structural aesthetics to an exciting new reactivity chemistry of coordinated ligands. Eur. J. Inorg. Chem., 2009, 3361-3391.

(32) Mayans, J.; Martin, A.; Font-Bardia, M.; Escuer, A. Chiral tetranuclear Ni ${ }^{\mathrm{II}}$ clusters derived from Schiff bases and azido co-ligands. Polyhedron, 2018, 150, 10-14.

(33) Mayans, J.; Font-Bardia, M.; Escuer, A. Chiroptical and magnetic properties of starshaped $\mathrm{Fe}^{\mathrm{III}} 4$ complexes from chiral Schiff bases. Structural and magnetic correlations based on continuous shape measures. Dalton Trans. 2018, 47, 8392-8401.

(34) a) Fan, L. L.; Guo, F. S.; Yun, L.; Lin, Z.-J.; Herchel, R.; Leng, J. D.; Ou, Y. C.; Tong, M. L. Chiral transition metal clusters from two enantiomeric Schiff base ligands. Synthesis, structures, CD spectra and magnetic properties. Dalton Trans. 2010, 39, 1771-1780.

(35) Song, Y.; Zhang, G.; Qin, X.; Gao, Y.; Ding, S.; Wang, Y.; Du, C.; Liu, Z. Chiral $\left[\mathrm{NaMn}^{\mathrm{II}} \mathrm{Mn}^{\mathrm{III}}{ }_{3}\right]$ and $\left[\mathrm{Na}_{2} \mathrm{Mn}_{2}{ }_{2} \mathrm{Mn}^{\mathrm{III}}{ }_{6}\right]$ clusters constructed by chiral multidentate Schiff-base ligands: synthesis, structures, CD spectra and magnetic properties. Dalton Trans. 2014, 43, 38803887.

(36) Halcrow, M. A.; Sun, J. S.; Huffman, J. C.; Christou, G. Structural and magnetic properties of $\left[\mathrm{Ni}_{4}(. \mathrm{mu} .3-\mathrm{OMe})_{4}(\mathrm{dbm}) 4(\mathrm{MeOH})_{4}\right]$ and $\left[\mathrm{Ni}_{4}\left(. \text { eta.1, mu.3- } \mathrm{N}_{3}\right)_{4}(\mathrm{dbm})_{4}(\mathrm{EtOH})_{4}\right]$. Magnetostructural Correlations for $\left[\mathrm{Ni}_{4} \mathrm{X}_{4}\right]^{4+}$ Cubane Complexes. Inorg. Chem. 1995, 34, $4167-$ 4177.

(37) El Fallah, M. S.; Rentschler, E.; Caneschi, A.; Gatteschi, D. Synthesis, crystal structure and magnetic properties of the tetranuclear complex $\left[\mathrm{Ni}_{4}\left(\mathrm{OCH}_{3}\right)_{4}(\mathrm{dbm})_{4}\left(\mathrm{CH}_{3} \mathrm{OH}\right)_{4}\right]_{2}\left(\mathrm{C}_{2} \mathrm{H}_{5}\right)_{2} \mathrm{O}$ Inorg. Chim. Acta 1996, 247, 231-235. 
(38) Escuer, A.; Font-Bardia, M.; Kumar, S. B.; Solans, X.; Vicente, R. Two new nickel(II) cubane compounds derived from pyridine-2-methoxide (Pym): $\left\{\mathrm{Ni}_{4}\left(\mathrm{Pym}_{4}\right)_{4} \mathrm{Cl}_{4}\left(\mathrm{CH}_{3} \mathrm{OH}\right)_{4}\right\}$ and $\left\{\mathrm{Ni}_{4}(\mathrm{Pym})_{4}\left(\mathrm{~N}_{3}\right)_{4}\left(\mathrm{CH}_{3} \mathrm{OH}\right)_{4}\right\}$. Crystal structures and magnetic properties. Polyhedron 1999, 18, 909-914.

(39) Clemente-Juan, J. M.; Chansou, B.; Donnadieu, B.; Tuchagues, J. P. Synthesis, structure, and magnetic properties of the low-symmetry tetranuclear cubane-like nickel complex $\left[\mathrm{Ni}_{4}\left(\right.\right.$ pypentO) $($ pym $\left.)\left(\mu_{3}-\mathrm{OH}\right)_{2}(\mu-\mathrm{Oac})_{2}(\mathrm{NCS})_{2}\left(\mathrm{OH}_{2}\right)\right]$. Inorg. Chem. 2000, 39, 5515-5519.

(40) Sieber, A.; Boskovic, C.; Bircher, R.; Waldmann, O.; Ochsenbein, S. T.; Chaboussant, G.; Gudel, H. U.; Kirchner, N.; van Slageren, J.; Wernsdorfer, W.; Neels, A.; Stoeckli-Evans, H.; Janssen, S.; Juranyi, F.; Mutka, H. Synthesis and spectroscopic characterization of a new family of Ni4 spin clústers. Inorg. Chem. 2005, 44, 4315-4325.

(41) Afrati, T.; Dendrinou-Samara, C.; Raptopoulou, C. R.; Terzis, A.; Tangoulis, V.; Kessissoglou, D. P. A Tetranuclear mixed-valent $\mathrm{Mn}_{3}{ }_{3} \mathrm{Mn}^{\mathrm{IV}}$ compound with a $\left(\mu_{4}-\mathrm{O}\right) \mathrm{Mn}_{4}$ core. Angew. Chem., Int. Ed. 2002, 41, 2148-2150.

(42) Scott, R. T. W.; Parsons, S.; Murugesu, M.; Wernsdorfer, W.; Christou, G.; Brechin, E. K. Linking centered manganese triangles into larger clusters: a $\left\{\mathrm{Mn}_{32}\right\}$ truncated cube. Angew. Chem., Int. Ed., 2005, 44, 6540-6543.

(43) Millos, C. J.; Piligkos, S.; Bell, A. R.; Laye, R. H.; Teat, S. J.; Vicente, R.; McInnes, E.; Escuer, A.; Perlepes, S. P.; Winpenny, R. E. P. A rare mixed-valence state manganese(II/IV) tetranuclear cage formed using phenyl 2-pyridyl ketone oxime and azide as ligands. Inorg. Chem. Commun. 2006, 9, 638-641. 
(44) Karotsis, G.; Jones, L. F.; Papaefstathiou, G. S.; Collins, A.; Parsons, S.; Nguyen, T. D.; Evangelisti, M.; Brechin, E. K. Rare tetranuclear mixed-valent $\left[\mathrm{Mn}_{2}{ }_{2} \mathrm{Mn}^{\mathrm{IV}}{ }_{2}\right]$ clusters as building blocks for extended networks. Dalton Trans. 2008, 4917-4925.

(45) Stoumpos, C. C.; Stamatatos, T. C.; Sartzi, H.; Roubeau, O.; Tasiopoulos, A. J.; Nastopoulos, V.; Teat, S. J.; Christou, G.; Perlepes, S. P. Employment of methyl 2-pyridyl ketone oxime in manganese non-carboxylate chemistry: $\mathrm{Mn}_{2}{ }_{2} \mathrm{Mn}^{\mathrm{IV}}$ and $\mathrm{Mn}_{2}{ }_{2} \mathrm{Mn}^{\mathrm{III}} 6$ complexes. Dalton Trans. 2009, 1004-1015.

(46) Zhou, A. J. ; Liu, J. L.; Herchel, R.; Leng, J. D.; Tong, M. L. High-spin tetranuclear $\mathrm{Mn}_{2}{ }_{2} \mathrm{Mn}^{\mathrm{IV}}{ }_{2}$ clusters with unique $\mathrm{Mn}(\mathrm{II})-\mathrm{Mn}(\mathrm{IV})$ magnetic exchange: synthesis, structures and magnetism. Dalton Trans. 2009, 3182-3192.

(47) Langley, S. K.; Chilton, N. F.; Moubaraki, B.; Murray, K. S. Unusual oxidation state distributions observed for two mixed-valence heptanuclear manganese disc-like clusters. Dalton Trans. 2012, 41, 9789-9796.

(48) Adebayo, O. A.; Abboud, K. A.; Christou, G. New mixed-valence $\mathrm{Mn}^{\mathrm{II}} 4 \mathrm{Mn}^{\mathrm{IV}}$ clusters from an unusual ligand transformation. Polyhedron 2017, 122, 71-78. 


\section{For Table of Contents Use Only}

\section{Chiral oxazolidine complexes derived from phenolic Schiff bases.}

Júlia Mayans, Daniel Gómez, Mercè Font-Bardia, Albert Escuer, ${ }^{*}$

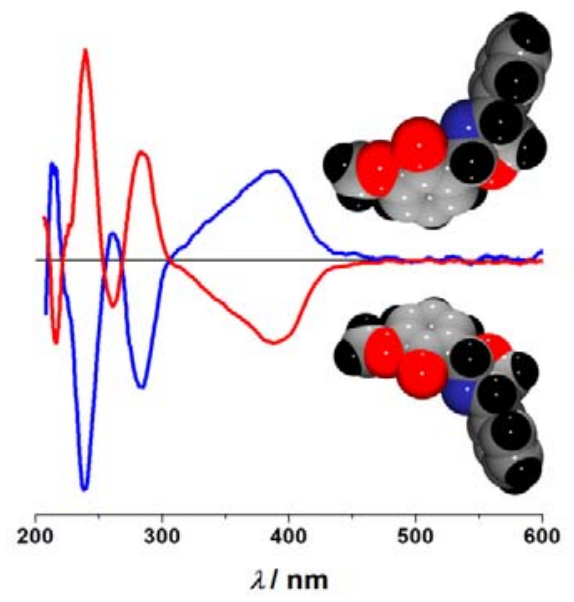

Polynuclear complexes derived from unprecedented chiral oxazolidines have been characterized.

The comparison among pyridine- or phenol-oxazolidines derived from Schiff bases point out its different reactivity. 